\title{
A eficácia dos novos tratamentos de hormonioterapia na sobrevida livre de progressão de pacientes com câncer de mama metastático RH+/HER2-: uma revisão
}

\section{sistemática}

\author{
The effectiveness of new hormone therapy treatments on progression-free survival of patients with
} HR+/HER2- metastatic breast cancer: a systematic review

La efectividad de los nuevos tratamientos de terapia hormonal en la supervivencia libre de

progresión de pacientes con cáncer de mama metastásico RH+/HER2-: una revisión sistemática

Recebido: 18/10/2021 | Revisado: 23/10/2021 | Aceito: 24/10/2021 | Publicado: 26/10/2021

\author{
Lucas Rodrigues da Silva \\ ORCID: https://orcid.org/0000-0002-5575-7081 \\ Instituto Presidente Antônio Carlos, Brasil \\ E-mail: lucas1905.lr@gmail.com \\ Nathália de Lima Queiroz \\ ORCID: https://orcid.org/0000-0003-4854-7294 \\ Instituto Presidente Antônio Carlos, Brasil \\ E-mail: nathalialimapsicologia@gmail.com \\ Marina dos Santos Menezes \\ ORCID: https://orcid.org/0000-0002-4302-4366 \\ Instituto Presidente Antônio Carlos, Brasil \\ E-mail: marinadiversos@gmail.com \\ Janaina Alves de Carvalho \\ ORCID: https://orcid.org/0000-0002-4656-662X \\ Instituto Presidente Antônio Carlos, Brasil \\ E-mail: janaina.alves66@gmail.com \\ Areta Agostinho Rodrigues de Souza \\ ORCID: https://orcid.org/0000-0002-5587-9310 \\ Instituto Presidente Antônio Carlos, Brasil \\ E-mail: areta.souza@itpacpalmas.com.br
}

\begin{abstract}
Resumo
Objetivo: O câncer de mama é o tipo de neoplasia que mais acomete as mulheres, ficando atrás apenas dos cânceres de pele não melanoma. Os inibidores de quinase dependente de ciclina 4 e 6 (CDK 4/6) são a mais recente opção de terapia hormonal para as pacientes com câncer de mama metastático RH+/HER2-. Dessa forma, o presente estudo busca compreender a eficácia dos novos tratamentos de hormonioterapia na sobrevida livre de progressão de pacientes com câncer de mama metastático RH+/HER2-. Metodologia: Foi realizada uma revisão sistemática da literatura utilizando o modelo Preferred Reporting Items for Systematic Reviews and Meta-Analyses (PRISMA), mediante buscas nas bases de dados Pubmed, Lilacs, BioOne, The Cochrane Library, Scielo, IBECS e Medline. Resultados: A combinação de inibidores de CDK 4/6 com inibidores da aromatase demonstrou melhores resultados quanto à sobrevida livre de progressão para tratamento de primeira linha do câncer de mama metastático RH+/HER2-, sendo adotada pelas principais diretrizes das sociedades americana e europeia de Oncologia. A melhor sobrevida livre de progressão média foi de 28,2 meses, alcançada com a combinação abemaciclibe mais letrozol. No que se refere à sobrevida global, o melhor tempo obtido foi de 54,1 meses com fulvestranto em monoterapia. Conclusão: Os inibidores de CDK 4/6 são novidade no que diz respeito ao tratamento do câncer de mama metastático RH+/HER2-, tendo grandes resultados quanto à sobrevida livre de progressão quando combinados com inibidores de aromatase ou fulvestranto.
\end{abstract}

Palavras-chave: Câncer de mama; Terapia hormonal; Sobrevida; Inibidores de quinase dependente de ciclina.

\begin{abstract}
Objective: Breast cancer is the most prevalent cancer that affects women, second only to non-melanoma skin cancers. Cyclin-dependent kinase 4 and 6 (CDK 4/6) inhibitors are the latest hormone therapy option for patients with HR+/HER2- metastatic breast cancer. Thus, the present study seeks to understand the effectiveness of new hormone therapy treatments in the progression-free survival of patients with HR+/HER2- metastatic breast cancer. Methodology: A systematic review of literature was performed following the Preferred Reporting Items for Systematic Reviews and Meta-Analyses (PRISMA) model, through database searches on Pubmed, Lilacs, BioOne, The Cochrane Library,
\end{abstract}


Scielo, IBECS and Medline. Results: The combination of CDK 4/6 inhibitors with aromatase inhibitors has demonstrated better results regarding progression-free survival for first-line treatment of HR+/HER2- metastatic breast cancer, being adopted by the main guidelines of American and European societies of Oncology. The best average progression-free survival was 28.2 months, achieved with the abemaciclib plus letrozole combination. As regards overall survival, the best time obtained was 54.1 months with fulvestrant monotherapy. Conclusion: CDK 4/6 inhibitors are novelty with regard to the treatment of HR+/HER2- metastatic breast cancer, having great results for progressionfree survival when combined with aromatase inhibitors or fulvestrant.

Keywords: Breast cancer; Hormone therapy; Survival; Cyclin-dependent kinase inhibitors.

\section{Resumen}

Objetivo: El cáncer de mama es el cáncer que más afecta a las mujeres, detrás de solo los cánceres de piel no-melanomas. Los inhibidores de la quinasa dependiente de la ciclina 4 y 6 (CDK 4/6) son la opción de terapia hormonal más reciente para las pacientes con cáncer de mama metastásico RH+/HER2-. Por lo tanto, el presente estudio busca comprender la efectividad de los nuevos tratamientos de terapia hormonal en la supervivencia libre de progresión de las pacientes con cáncer de mama metastásico RH+/HER2-. Metodología: Se realizó una revisión sistemática de la literatura utilizando el modelo Preferred Reporting Items for Systematic Reviews and Meta-Analyses (PRISMA), a través de búsquedas en las bases de datos Pubmed, Lilacs, BioOne, The Cochrane Library, Scielo, IBECS y Medline. Resultados: La combinación de los inhibidores de CDK 4/6 con inhibidores de la aromatasa ha demostrado mejores resultados en la supervivencia libre de progresión para el tratamiento de primera línea del cáncer de mama metastásico RH+/HER2-, siendo adoptados por las principales directrices de las sociedades americana y europea de Oncología. La mejor supervivencia libre de progresión media fue de 28,2 meses, logrado con la combinación de abemaciclib más letrozol. En cuanto a la supervivencia global, el mejor tiempo obtenido fue de 54,1 meses con fulvestrant en monoterapia. Conclusión: Los inhibidores de la CDK 4/6 son nuevos en el tratamiento del cáncer de mama metastásico RH+/HER2y tienen excelentes resultados en la supervivencia libre de progresión cuando se combinan con inhibidores de la aromatasa o fulvestrant.

Palabras clave: Cáncer de mama; Terapia hormonal; Supervivencia; Inhibidores de la quinasa dependiente de la ciclina.

\section{Introdução}

O câncer de mama é o tipo de neoplasia que mais acomete as mulheres, ficando atrás apenas dos cânceres de pele não melanoma. De acordo com o Instituto Nacional de Câncer José Alencar Gomes da Silva [INCA] (2019b), a estimativa de incidência anual do câncer de mama em mulheres é de 66.280, no período de 2020 a 2022. Já em relação à mortalidade, no ano de 2019 o número devido ao câncer de mama foi de 18.608 mulheres, representando uma taxa de 2,99\% no Brasil (Tabela 1).

Tabela 1 - Mortalidade proporcional não ajustada por câncer de mama, mulheres, Brasil, entre 2011 e 2019.

\begin{tabular}{cccc}
\hline Ano & Total de óbito & Total de óbito para câncer & \% \\
\hline 2011 & 504.415 & 13.225 & 2,62 \\
2012 & 509.885 & 13.591 & 2,67 \\
2013 & 523.195 & 14.206 & 2,72 \\
2014 & 532.362 & 14.622 & 2,75 \\
2015 & 554.383 & 15.403 & 2,78 \\
2016 & 572.359 & 16.069 & 2,81 \\
2017 & 577.573 & 16.724 & 2,90 \\
2018 & 582.457 & 17.572 & 3,02 \\
2019 & 603.726 & 18.608 & 2,99 \\
\hline
\end{tabular}

Fonte: INCA (2021a).

Os dados mais importantes, a serem analisados na Tabela 1, são os números relacionados à mortalidade de mulheres com câncer de mama nos últimos anos, visto que houve um aumento de mais de 5.000 casos, no número de óbitos por ano entre 2011 e 2019.

Os fatores de risco são aqueles que, quando associados a causas ambientais, hereditárias ou como resultado de hábitos, aumentam a chance de uma pessoa sadia desenvolver determinada doença. Os fatores de risco para o câncer de mama são idade, gênero feminino e cor da pele branca. Conforme o INCA (2021b) aponta, a idade representa uma das mais importantes causas e 
aponta que cerca de quatro em cada cinco casos ocorrem após a faixa etária dos 50 anos. As outras situações que contribuem para o risco da doença estão listadas na tabela abaixo (Tabela 2).

Tabela 2 - Fatores de risco para o câncer de mama.

\begin{tabular}{|c|c|c|}
\hline $\begin{array}{c}\text { Fatores de risco ambientais e } \\
\text { comportamentais }\end{array}$ & $\begin{array}{c}\text { Fatores da história reprodutiva e } \\
\text { hormonal }\end{array}$ & Fatores genéticos e hereditários \\
\hline Obesidade (IMC > $30 \mathrm{~kg} / \mathrm{m}^{2}$ ) e sobrepeso. & Menarca precoce. & História familiar de câncer de ovário. \\
\hline $\begin{array}{l}\text { Inatividade física (não realizar } 150 \\
\text { minutos por semana de atividade física). }\end{array}$ & Nuliparidade. & $\begin{array}{l}\text { Casos de câncer de mama na família } \\
\text { (principalmente antes dos } 50 \text { anos). }\end{array}$ \\
\hline Consumo de bebida alcoólica. & Gestação tardia. & $\begin{array}{l}\text { História familiar de câncer de mama } \\
\text { em homens. }\end{array}$ \\
\hline Tabagismo. & $\begin{array}{l}\text { Uso de contraceptivos hormonais } \\
\text { (estrogênio - progesterona). } \\
\text { Ter realizado reposição hormonal pós } \\
\text { menopausa, (por mais de } 5 \text { anos). }\end{array}$ & \\
\hline
\end{tabular}

Fonte: INCA (2021b).

Ao analisar a Tabela 2, é necessário observar a importância dos fatores de risco ambientais, comportamentais, genéticos e hereditários, bem como a história reprodutiva e hormonal, para o câncer de mama nas mulheres.

Atualmente, para o estudo sobre câncer de mama, deve-se compreender suas subdivisões histológica, imunoistoquímica e molecular. A subdivisão histológica abrange lesões in situ, lobular, microinvasivo e invasivo, porém não é mais utilizada no contexto do tratamento clínico. A classificação imunoistoquímica é composta pela presença ou ausência dos receptores hormonais $(\mathrm{RH})$, receptor de estrogênio (RE), receptor de progesterona (RP), e do receptor do fator de crescimento epidérmico humano 2 (HER2). Já a subdivisão molecular engloba o tipo luminal A, sendo RE e RP positivo, HER2 negativo e baixo índice Ki67; o tipo luminal B, sendo RE positivo, RP negativo ou baixo positivo, HER2 positivo ou negativo e alto índice Ki67; tipo com superexpressão de HER2, sendo HER2 superexpressado ou amplificado, RE e RP negativos; e o último subtipo, o triplo negativo, quando não há RE, RP e HER2 positivos (Goldhirsch et al., 2011).

Estabelecido o diagnóstico do câncer de mama é necessário definir com precisão a extensão da doença, esta faz-se por meio do estadiamento, ou seja, é preciso saber em que fase a doença se encontra e qual o tipo de tumor. Podem incluir: cirurgia e radioterapia, que fazem parte do tratamento local, ou quimioterapia, hormonioterapia e terapia biológica (terapia alvo), que fazem parte do tratamento sistêmico (Portaria conjunta n. 19, 2018).

A Sociedade Brasileira de Oncologia Clínica [SBOC] (2021) preconiza que o tratamento de primeira linha do câncer de mama metastático RH+/HER2-, tem como base a hormonioterapia, na qual as opções de escolha são:

- $\quad$ Inibidor de aromatase (IA);

- Fulvestranto em monoterapia;

- Fulvestranto mais anastrozol.

Outras opções alternativas são:

- $\quad$ IA em monoterapia;

- Tamoxifeno.

As opções de monoterapia são consideradas principalmente em pacientes com doença metastática não-visceral virgem de tratamento hormonal. 
Com relação às opções de drogas endócrinas, estas incluem os inibidores de aromatase (IAs) não esteroidais que são anastrozol, letrozol, ou o IA esteroidal exemestano e ainda agentes que agem no receptor de estrogênio como tamoxifeno e fulvestranto. Há ainda o uso dos inibidores de quinase dependente de ciclina 4 e 6 (CDK 4 e 6), inibidores do alvo mecanístico da rapamicina (mTOR) e inibidores da fosfatidilinositol 3-quinase (PI3K) combinados com hormonioterapia (HT), estas são dirigidas aos mecanismos de resistência à terapia endócrina (TE), mostrando eficácia na prática clínica (SBOC, 2021). Dessa forma, o presente estudo busca compreender a eficácia dos novos tratamentos de hormonioterapia na sobrevida livre de progressão de pacientes com câncer de mama metastático RH+/HER2-.

\section{Metodologia}

A revisão sistemática da literatura foi realizada utilizando-se do modelo Preferred Reporting Items for Systematic Reviews and Meta-Analyses (PRISMA). O modelo PRISMA é estruturado em um checklist de 27 itens e em um fluxograma ordenado em 4 etapas, para maior transparência da sistematização e redução dos vieses de pesquisa, visando a melhor qualidade da presente pesquisa (Galvão, Pansani, \& Harrad, 2015).

\section{1 Ética}

Este estudo dispensa a necessidade do Termo de Consentimento Livre e Esclarecido (TCLE) e a submissão ao Conselho de Ética, pois trata-se de uma revisão sistemática da literatura, realizada exclusivamente com artigos publicados em revistas científicas.

\subsection{Estratégia de busca dos estudos}

As pesquisas dos artigos foram realizadas em conjunto, pelos quatro autores, nas seguintes bases de dados: Pubmed, Lilacs, BioOne, The Cochrane Library, Scielo, IBECS e Medline. A busca foi realizada por meio das palavras-chaves: "câncer de mama metastático" e "terapia hormonal"; "câncer de mama metastático" e "inibidor de ciclina"; "câncer de mama metastático" "inibidor de PI3K"; "câncer de mama metastático" e "inibidor de mTOR"; "metastatic breast cancer" e "hormone therapy"; metastatic breast cancer" e "cyclin inhibitor"; "metastatic breast cancer" e "PI3K inhibitor"; "metastatic breast cancer" e “mTOR inhibitor". Foram selecionados os artigos publicados entre 2011 e 2021, nos idiomas português, inglês e espanhol e que se encontram disponíveis para leitura na íntegra.

\subsection{Critérios de inclusão}

Para o desenvolvimento da pesquisa, entraram como critérios de inclusão:

- Os artigos encontrados na íntegra;

- A partir de pesquisas com as palavras-chaves descritas acima em língua inglesa, portuguesa e espanhola;

- Obras publicadas entre 2011 e 2021;

- Artigos que tenham como população estudada, mulheres com câncer de mama metastático sem terapia prévia para a doença metastática;

\subsection{Critérios de exclusão}

Como critérios de exclusão entraram:

- Os artigos que não foram encontrados para leitura na íntegra;

- Publicações duplicadas; 
- Os artigos que apresentaram avaliação ruim;

- Os trabalhos de revisão sistemática, simples e os bibliográficos;

- Trabalhos que apresentaram relato de caso único;

- $\quad$ Artigos que não abordaram o tema e objetivos de pesquisa;

- Os artigos escritos antes de 2011, que não sejam em língua portuguesa, inglesa ou espanhola;

- Trabalhos que fogem ao tema desta revisão sistemática;

- As pesquisas que tenham como população estudada, homens com câncer de mama e mulheres com câncer de mama inicial ou localmente avançado, ou com algum tipo de terapia prévia para doença metastática.

\subsection{Seleção dos estudos}

Os acadêmicos se reuniram para fazer a coleta de artigos em diferentes bases de dados. Primeiramente foi realizado o levantamento da quantidade de artigos encontrados, utilizando as palavras-chaves selecionadas pelo grupo (Tabelas 3 e 4 ). Em seguida, foi realizada a filtragem dos artigos por ano e idioma, utilizando as ferramentas disponíveis nas bases de dados. Os estudos identificados foram, então, submetidos a análise para exclusão de artigos duplicados. Após a remoção de duplicidades, os trabalhos restantes foram selecionados por título para leitura de resumos e exclusão daqueles que não atenderam aos critérios de elegibilidade. Por fim, realizou-se a análise a partir da leitura na íntegra dos artigos escolhidos anteriormente. Com relação aos artigos nos quais houve divergência, os autores decidiram por meio de consenso, realizado em sete estudos. Buscando minimizar possíveis vieses de avaliação dos estudos, os pesquisadores procederam com a leitura dos artigos e avaliação de forma independente, comparando posteriormente suas conclusões.

Tabela 3 - Distribuição das referências bibliográficas obtidas nas bases de dados Medline, PUBMED, LILACS, BIOONE, Scielo, IBECS, The Cochrane Library, segundo as palavras-chave selecionadas, Brasil, 2021.

\begin{tabular}{|c|c|c|c|c|c|c|c|}
\hline \multirow[b]{2}{*}{ Palavras-chave } & \multicolumn{7}{|c|}{ Plataformas } \\
\hline & Medline & PubMed & Lilacs & IBECS & Scielo & $\begin{array}{l}\text { The Cochrane } \\
\text { Library }\end{array}$ & BioOne \\
\hline $\begin{array}{l}\text { Câncer de mama metastático; terapia } \\
\text { hormonal. }\end{array}$ & 743 & 1 & 4 & 4 & 0 & 0 & 0 \\
\hline $\begin{array}{l}\text { Metastatic breast cancer; hormone } \\
\text { therapy. }\end{array}$ & 2.998 & 3.327 & 9 & 7 & 3 & 1.077 & 0 \\
\hline $\begin{array}{l}\text { Câncer de mama metastático; } \\
\text { inibidor de ciclina. }\end{array}$ & 123 & 0 & 0 & 0 & 0 & 0 & 0 \\
\hline $\begin{array}{l}\text { Metastatic breast cancer; cyclin } \\
\text { inhibitor. }\end{array}$ & 533 & 545 & 0 & 1 & 0 & 95 & 0 \\
\hline $\begin{array}{l}\text { Câncer de mama metastático; } \\
\text { inibidor de PI3K. }\end{array}$ & 5 & 0 & 0 & 0 & 0 & 0 & 0 \\
\hline $\begin{array}{l}\text { Metastatic breast cancer; PI3K } \\
\text { inhibitor. }\end{array}$ & 15 & 385 & 0 & 0 & 0 & 124 & 0 \\
\hline $\begin{array}{l}\text { Câncer de mama metastático; } \\
\text { inibidor de mTOR. }\end{array}$ & 90 & 0 & 0 & 1 & 0 & 0 & 0 \\
\hline $\begin{array}{l}\text { Metastatic breast cancer; mTOR } \\
\text { inhibitor. }\end{array}$ & 357 & 341 & 0 & 1 & 0 & 102 & 0 \\
\hline
\end{tabular}


A Tabela 3 evidencia a distribuição das buscas realizadas nas bases de dados de acordo com as palavras-chave utilizadas. Nota-se que foi obtido maior número de resultados com os termos “metastatic breast cancer" e "hormone therapy". Os resultados foram resumidos na Tabela 4.

Tabela 4 - Total de artigos encontrados em relação às bases de dados selecionadas, Brasil, 2021.

\begin{tabular}{lc}
\hline \multicolumn{1}{c}{ Bases de dados } & Quantidade \\
\hline PUBMED & 4.599 \\
LILACS & 13 \\
BIOONE & 0 \\
THE COCHRANE LIBRARY & 1.398 \\
SCIELO & 3 \\
IBECS & 14 \\
MEDLINE & 4.864 \\
\hline \multicolumn{2}{c}{ Total } \\
\hline
\end{tabular}

Source: Authors (2021).

A Tabela 4, traz o total de artigos de acordo com a base de dados utilizados. É possível observar que as bases de dados Medline, PubMed e The Cochrane Library concentraram a maior parte dos resultados obtidos na pesquisa.

\subsection{Processo de extração de dados}

Foi realizada a leitura dos artigos e resumo de seus pontos-chave, com ano de publicação, autoria, título, objetivos de estudo, resultados encontrados e conclusões obtidas. Posteriormente foi realizada análise de acordo com as referências, pesquisadores envolvidos e opinião dos pesquisadores sobre os artigos.

\section{Resultados}

Inicialmente foram identificados 10.891 artigos nas bases de dados PubMed, Medline, The Cochrane Library, BioOne, LILACS, Scielo e IBECS (Figura 1). Após a identificação, fizemos a remoção das duplicatas, ficando para a análise de título 6.387 artigos. Fazendo a análise de títulos foram excluídos 5.947, restando 440 artigos para realização de análise de resumos. Posteriormente, foram selecionados para a leitura na íntegra 120 artigos. Nessa etapa, foram excluídos 96 trabalhos. Finalmente, 24 estudos foram selecionados para compor a presente revisão (Quadro 1). 
Figura 1 - Organograma referente ao processo de seleção de artigos para revisão sistemática de literatura baseada no método PRISMA.

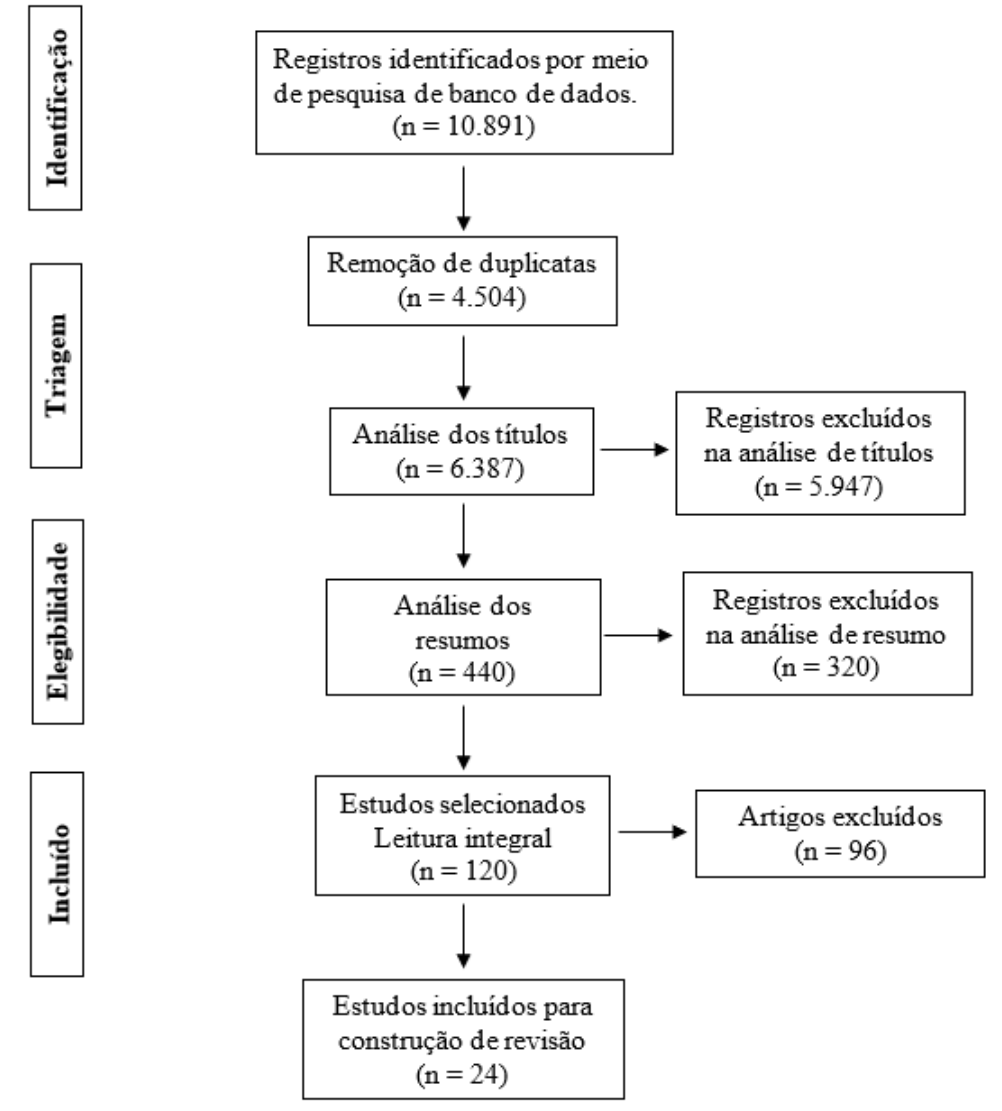

Source: Authors (2021).

A Figura 1 representa o organograma obtido a partir do processo de seleção de artigos para a revisão sistemática de literatura, sendo baseado no método PRISMA.

Assim sendo, este estudo consiste em uma revisão sistemática da literatura, englobando artigos originais que remetem ao tratamento de primeira linha do câncer de mama metastático RH+/HER2-. Destes, 62,5\% $(\mathrm{n}=15)$ possuem delineamento de ensaio clínico randomizado, prospectivo, de fases 2 ou 3, e 37,5\% (n = 9) são estudos observacionais retrospectivos de prontuários. Quanto ao local de pesquisa, $58,3 \%(\mathrm{n}=14)$ foram estudos multicêntricos internacionais, conferindo uma população mais diversa. Em média, os trabalhos reuniram 400 pacientes (54,2\% até 400 pacientes e 45,8\% acima de 400 pacientes), uma amostra significativa, uma vez que o câncer de mama RH+/HER2- é o subtipo molecular mais prevalente.

Com relação às intervenções farmacológicas testadas, as principais foram palbociclibe mais letrozol $(\mathrm{n}=7)$, ribociclibe mais letrozol $(n=5)$, abemaciclibe mais inibidor da aromatase $(n=4)$ e abemaciclibe mais fulvestranto $(n=4)$. No que se refere à tratamento de primeira linha para o câncer de mama metastático RH+/HER2- e à melhor sobrevida livre de progressão (SLP), a terapia combinada de inibidores de CDK 4 e 6 (palbociclibe, abemaciclibe e ribociclibe) com IAs (anastrozol, letrozol) apresentaram maior efetividade do que a monoterapia. Também foi observado que no grupo de mulheres virgens de outros tratamentos, houve uma melhora significativa no resultado ao utilizar fulvestranto, um modulador seletivo dos receptores de estrogênio (MSRE), em combinação com o abemaciclibe.

Por fim, 8 artigos $(33,3 \%)$ analisaram a sobrevida global (SG) dos tratamentos avaliados. Foram evidenciadas as sobrevidas globais das combinações fulvestranto mais anastrozol (54,1 meses) e abemaciclibe mais fulvestranto (46,7 meses), já a associação de palbociclibe mais letrozol, apesar de ter sua sobrevida global avaliada, não foi possível estimá-la durante o período abrangido. 
Quadro 1 - Sumário dos artigos incluídos nesta revisão sistemática.

\begin{tabular}{|c|c|c|c|c|c|}
\hline Ano & Local & Autor & Título & Objetivo & Conclusão \\
\hline 2012 & Multinacional & Robertson et al. & $\begin{array}{l}\text { Fulvestrant } 500 \mathrm{mg} \text { versus anastrozole } \\
1 \mathrm{mg} \text { for the first-line treatment of } \\
\text { advanced breast cancer: follow-up } \\
\text { analysis from the randomized 'FIRST' } \\
\text { study. }\end{array}$ & $\begin{array}{l}\text { Relatar os resultados da análise } \\
\text { do tempo para progressão no } \\
\text { estudo FIRST. }\end{array}$ & $\begin{array}{l}\text { Este estudo de fase } 2 \text {, randomizado e aberto foi realizado com } 205 \text { pacientes que receberam } \\
\text { fulvestranto } 500 \mathrm{mg} \text { ( } 500 \mathrm{mg} / \mathrm{mês} \text { por via intramuscular mais } 500 \mathrm{mg} \text { no dia } 14 \text { do mês } 1) \\
\text { ou anastrozol ( } 1 \mathrm{mg} / \text { dia oralmente). A análise de acompanhamento foi realizada quando } \\
79,5 \% \text { dos pacientes interromperam o tratamento do estudo. média TTP foi de } 23,4 \text { meses } \\
\text { para fulvestranto versus } 13,1 \text { meses para anastrozol e; uma redução de } 34 \% \text { no risco de } \\
\text { progressão (perigo proporção 0,66; Intervalo de confiança de } 95 \%: 0,47,0,92 ; \mathrm{P}=0,01 \text { ) } \\
\text { Simultaneamente, esses resultados indicaram um benefício de eficácia para fulvestranto } 500 \\
\text { mg comparado com anastrozol como terapia endócrina de primeira linha para pacientes com } \\
\text { RH câncer de mama avançado. }\end{array}$ \\
\hline 2015 & Multinacional & Ellis et al. & $\begin{array}{l}\text { Fulvestrant } 500 \mathrm{mg} \quad \text { Versus } \\
\text { Anastrozole } 1 \mathrm{mg} \text { for the First-Line } \\
\text { Treatment of Advanced Breast Cancer: } \\
\text { Overall Survival Analysis From the } \\
\text { Phase II FIRST Study. }\end{array}$ & $\begin{array}{l}\text { Comparar a sobrevida global } \\
\text { (SG) para fulvestranto } 500 \mathrm{mg} \\
\text { versus anastrozol como terapia } \\
\text { endócrina de primeira linha para } \\
\text { câncer de mama avançado. }\end{array}$ & $\begin{array}{l}\text { Foi realizado um estudo de primeira linha fulvestranto comparando tratamentos endócrinos } \\
\text { (FIRST) de fase II, em um ensaio clínico randomizado multicêntrico e aberto. Foram } \\
\text { selecionadas } 205 \text { mulheres na pós menopausa com receptor de estrogênio positivo, câncer } \\
\text { de mama localmente avançado/metastático que não tiveram terapia anterior. As pacientes } \\
\text { receberam fulvestranto } 500 \mathrm{mg} \text { (dias, } 0,14,28 \text { e a cada } 28 \text { dias depois) ou anastrozol } 1 \mathrm{mg} \\
\text { (diário). } \\
\text { Em relação à sobrevida global, as taxas foram melhoradas no grupo de fulvestranto } 500 \mathrm{mg} \\
(64 \%) \text { em comparação com o anastrozol } 1 \mathrm{mg}(58 \%) \text {. } \\
\text { Foi observado que há muitas limitações na análise do sistema operacional, mas que os } \\
\text { resultados sugerem que há melhores taxas de sobrevida global nas pacientes que receberam } \\
\text { fulvestranto } 500 \mathrm{mg} \text {, comparado ao anastrozol, porém aguardam a perspectiva confirmação } \\
\text { no estudo de fase III, duplo-cego FALCONI. }\end{array}$ \\
\hline 2015 & Multinacional & Finn et al. & $\begin{array}{l}\text { The cyclin-dependent kinase } 4 / 6 \\
\text { inhibitor palbociclib in combination } \\
\text { with letrozole versus letrozole alone as } \\
\text { first-line treatment of oestrogen } \\
\text { receptor-positive, HER2-negative, } \\
\text { advanced breast cancer (PALOMA- } \\
\text { 1/TRIO-18): a randomised phase } 2 \\
\text { study. }\end{array}$ & $\begin{array}{l}\text { Avaliar a segurança e eficácia da } \\
\text { combinação de palbociclibe e } \\
\text { letrozol comparado com letrozol } \\
\text { em monoterapia como } \\
\text { tratamento de primeira linha de } \\
\text { mulheres com câncer de mama } \\
\text { avançado RH+/HER2-. }\end{array}$ & $\begin{array}{l}\text { Neste estudo internacional, de fase } 2 \text {, multicêntrico e randomizado aberto, foram analisadas } \\
\text { mulheres na pós-menopausa com câncer de mama avançado RH+/HER2-, divididas em duas } \\
\text { coortes. Na coorte } 1 \text {, as pacientes foram selecionadas com base apenas no estado do } \\
\text { biomarcador RE+ e HER2-, enquanto que na coorte } 2 \text {, foi necessário ter amplificação de } \\
\text { ciclina D1, perda de p16, ou ambos. } 165 \text { mulheres foram distribuídas aleatoriamente, } 84 \\
\text { para receber letrozol mais palbociclibe e } 81 \text { para letrozol em monoterapia. A SLP média do } \\
\text { grupo palbociclibe mais letrozol foi de } 20,2 \text { meses, e de } 10,2 \text { meses para o grupo de letrozol } \\
\text { em monoterapia. Entre as pacientes na coorte } 1 \text {, a SLP foi de } 26,1 \text { meses para a combinação } \\
\text { e } 5,7 \text { para a monoterapia de letrozol, enquanto que na coorte } 2 \text {, foi de } 18,1 \text { e } 11,1 \text { meses, } \\
\text { respectivamente. Este estudo de fase } 2 \text { evidenciou que o uso de palbociclibe mais letrozol } \\
\text { aumentou significativamente a SLP em mulheres com câncer de mama avançado } \\
\text { RH+/HER2-. }\end{array}$ \\
\hline 2016 & Multinacional & $\begin{array}{l}\text { Hortobagyi, } \\
\text { Stemmer, Burris, } \\
\text { \& Yap. }\end{array}$ & $\begin{array}{l}\text { Ribociclib as First-Line Therapy for } \\
\text { HR-Positive, Advanced Breast } \\
\text { Cancer. }\end{array}$ & $\begin{array}{l}\text { Apresentar os resultados da } \\
\text { análise provisória pré-planejada } \\
\text { do ensaio de Avaliação } \\
\text { Oncológica Mamária de } \\
\text { Eficácia e Segurança LEE011 } \\
\text { (Ribociclibe) (MONALEESA- } \\
\text { 2). }\end{array}$ & $\begin{array}{l}\text { Foi realizado um ensaio clínico randomizado, duplo-cego, de fase } 3 \text {, multinacional. A } \\
\text { pesquisa foi realizada com } 668 \text { pacientes que receberam ribociclibe oral mais letrozol ou } \\
\text { placebo mais letrozol. Nos resultados foi descrito que o intervalo livre de doença no início } \\
\text { do estudo foi de mais de } 24 \text { meses. Foi observado que a taxa de sobrevida livre de progressão } \\
\text { foi significativamente maior no grupo que recebeu ribociclibe, após } 12 \text { meses foi de } 72,8 \% \\
\text { e aos } 18 \text { meses de } 63,9 \% \text {. Já a taxa de sobrevida livre de progressão com o placebo foi aos } \\
12 \text { meses foi de } 60,9 \% \text { e aos } 18 \text { meses de } 42,2 \% \text {. Contudo, o estudo permanece cego para o } \\
\text { acompanhamento da sobrevida global. O estudo demonstrou alta sobrevida livre de }\end{array}$ \\
\hline
\end{tabular}




\begin{tabular}{|c|c|c|c|c|c|}
\hline & & & & & $\begin{array}{l}\text { progressão e maiores taxas de resposta com a adição do ribociclibe ao letrozol para o } \\
\text { tratamento de primeira linha nas mulheres com câncer de mama avançado RH+/ HER2-. }\end{array}$ \\
\hline 2016 & Multinacional & Robertson et al. & $\begin{array}{l}\text { Fulvestrant } 500 \mathrm{mg} \text { versus anastrazole } \\
1 \mathrm{mg} \text { for hormone receptor - positive } \\
\text { advanced breast cancer (FALCON): an } \\
\text { international, randomized, double - } \\
\text { blind, phase } 3 \text { trial. }\end{array}$ & $\begin{array}{l}\text { Avaliar a vantagem sobrevida } \\
\text { livre de progressão do } \\
\text { fulvestranto em relação ao } \\
\text { anastrozol, observada no estudo } \\
\text { FIRST. }\end{array}$ & $\begin{array}{l}\text { Foi realizado um ensaio clínico randomizado de fase } 3 \text {, duplo cego, abrangendo pacientes } \\
\text { com confirmação histológica de câncer de mama localmente avançado ou metastático RE+ } \\
\text { ou RP+ de } 113 \text { hospitais acadêmicos e centros comunitários em } 20 \text { países. No período de } \\
17 \text { de outubro de } 2012 \text { e } 11 \text { de julho de } 2014,524 \text { pacientes foram incluídos neste estudo. } \\
\text { Destes, } 462 \text { pacientes eram randomizados ( } 230 \text { para receber fulvestranto e } 232 \text { para receber } \\
\text { anastrozol). Concluiu -se que a sobrevida livre de progressão foi significativa mais tempo } \\
\text { no grupo fulvestranto do que no grupo anastrozol (razão de risco [RR] } 0,797 \text {, IC de } 95 \% \\
0,637-0,999, p=0,0486 \text { ). A sobrevida livre de progressão média foi de } 16,6 \text { meses (IC } 95 \% \\
13,33-20,99) \text { no grupo de fulvestranto versus } 13,8 \text { meses }(11,99-16,59) \text { no grupo anastrozol. } \\
\text { Concluiu-se que o uso do fulvestranto é mais eficaz para pacientes com câncer de mama } \\
\text { metastático ou localmente avançado que não receberam terapia endócrina anterior em } \\
\text { comparação com um inibidor de aromatase de terceira geração. }\end{array}$ \\
\hline 2016 & Multinacional & Rugo et al. & $\begin{array}{l}\text { Progression-free Survival Outcome Is } \\
\text { Independent of Objective Response in } \\
\text { Patients With Estrogen Receptor- } \\
\text { positive, Human Epidermal Growth } \\
\text { Factor Receptor 2-negative Advanced } \\
\text { Breast Cancer Treated With } \\
\text { Palbociclib Plus Letrozole Compared } \\
\text { With Letrozole: Analysis From } \\
\text { PALOMA-2. }\end{array}$ & $\begin{array}{l}\text { Examinar os desfechos clínicos } \\
\text { das pacientes no estudo } \\
\text { PALOMA-2 que atingiram uma } \\
\text { resposta objetiva confirmada em } \\
\text { comparação com aquelas que } \\
\text { não atingiram. }\end{array}$ & $\begin{array}{l}\text { PALOMA- } 2 \text { foi um estudo de fase } 3 \text { randomizado, controlado por placebo, duplo-cego, } \\
\text { multicêntrico em pacientes na pós-menopausa com câncer de mama avançado RE+/HER2-. } \\
\text { Um total de } 666 \text { pacientes participaram do estudo, e receberam palbociclibe mais letrozol } \\
(\mathrm{n}=444) \text { ou placebo mais letrozol }(\mathrm{n}=222) \text {. A SLP no braço palbociclibe foi de } 37,2 \text { meses } \\
\text { em pacientes com resposta objetiva e } 10,9 \text { meses naqueles sem resposta objetiva. Já no braço } \\
\text { placebo, a SLP foi de } 27,4 \text { meses nos com resposta objetiva, e } 5,6 \text { meses naqueles sem } \\
\text { resposta objetiva. O estudo concluiu que palbociclibe mais letrozol é uma opção terapêutica } \\
\text { efetiva para pacientes com câncer de mama avançado RH+/HER2-, independentemente de } \\
\text { a paciente ter atingido uma resposta objetiva ao tratamento. }\end{array}$ \\
\hline 2017 & Multinacional & Goetz et al. & $\begin{array}{l}\text { MONARCH 3: Abemaciclib As Initial } \\
\text { Therapy for Advanced Breast Cancer. }\end{array}$ & $\begin{array}{l}\text { Relatar os resultados do estudo } \\
\text { MONARCH 3, um estudo de } \\
\text { fase 3, controlado por placebo. }\end{array}$ & $\begin{array}{l}\text { Realizou-se um estudo de fase } 3 \text {, randomizado, duplo-cego de abemaciclibe ou placebo, } \\
\text { mais um inibidor da aromatase não esteroidal. O estudo incluiu } 493 \text { pacientes aleatoriamente } \\
\text { alocados para receber abemaciclibe mais inibidor de aromatase (n = 328) ou placebo mais } \\
\text { inibidor de aromatase ( } \mathrm{n}=165 \text { ). A SLP média não foi atingida no "braço" abemaciclibe, e } \\
\text { foi de } 14,7 \text { meses no "braço" placebo. O estudo concluiu que a combinação de abemaciclibe } \\
\text { e um IA aumentou a SLP significativamente, quando comparado com a monoterapia com } \\
\text { IA. Assim, o uso de abemaciclibe e IA demonstrou ser um tratamento inicial eficaz com um } \\
\text { perfil de segurança tolerável para mulheres na pós-menopausa com câncer de mama } \\
\text { avançado RH+/HER2-. }\end{array}$ \\
\hline 2018 & Multinacional & $\begin{array}{l}\text { O'Shaughnessy et } \\
\quad \text { al. }\end{array}$ & $\begin{array}{l}\text { Ribociclib plus letrozole versus } \\
\text { letrozole alone in patients with de novo } \\
\text { HR+, HER2- advanced breast cancer } \\
\text { in the randomized MONALEESA-2 } \\
\text { trial. }\end{array}$ & $\begin{array}{l}\text { Relatar os resultados da eficácia } \\
\text { e segurança de uma análise } \\
\text { prospectiva de subgrupo de } \\
\text { MONALEESA-2 em pacientes } \\
\text { com câncer de mama avançado } \\
\text { de novo. }\end{array}$ & $\begin{array}{l}\text { Nesta pesquisa foi usado o ensaio clínico MONALEESA- } 2 \text { de Fase III randomizado, duplo- } \\
\text { cego, envolvendo mulheres pós-menopausa com câncer de mama avançado RH+/HER2-. O } \\
\text { estudo foi realizado entre janeiro de } 2014 \text { e março de } 2015 \text { e contou com } 668 \text { pacientes que } \\
\text { receberam ribociclibe mais letrozol e placebo mais letrozol. Em relação à sobrevida livre de } \\
\text { progressão, a combinação de ribociclibe mais letrozol foi maior, comparada com o placebo } \\
\text { mais letrozol em pacientes com câncer de mama avançado de novo. Após } 12 \text { meses, a taxa } \\
\text { de sobrevida livre de progressão nos braços de ribociclibe mais letrozol foi de } 82 \% \text {, já o } \\
\text { placebo mais letrozol de } 66 \% \text {. Contudo, os resultados de sobrevida global eram imaturos no } \\
\text { momento da análise. }\end{array}$ \\
\hline 2018 & Multinacional & Sonke et al. & $\begin{array}{l}\text { Ribociclib with letrozole vs letrozole } \\
\text { alone in elderly patients with hormone } \\
\text { receptor-positive, HER2-negative }\end{array}$ & $\begin{array}{l}\text { Determinar a segurança e } \\
\text { eficácia do uso de ribociclibe } \\
\text { mais letrozol em pacientes }\end{array}$ & $\begin{array}{l}\text { Trata-se de um estudo de fase } 3 \text {, internacional, randomizado, duplo-cego, controlado por } \\
\text { placebo, com mulheres na pós-menopausa com câncer de mama recorrente ou metastático } \\
\text { RH+/HER2-. No estudo MONALEESA- } 2,668 \text { pacientes foram aleatoriamente alocadas no }\end{array}$ \\
\hline
\end{tabular}




\begin{tabular}{|c|c|c|c|c|c|}
\hline & & & $\begin{array}{l}\text { breast cancer in the randomized } \\
\text { MONALEESA-2 trial. }\end{array}$ & $\begin{array}{l}\text { idosas (> } 65 \text { anos) participantes } \\
\text { do estudo MONALEESA-2. }\end{array}$ & $\begin{array}{l}\text { braço ribociclibe mais letrozol }(\mathrm{n}=334) \text { ou placebo mais letrozol }(\mathrm{n}=334) \text {. Destas, } 295 \\
\text { tinham mais de } 65 \text { anos, sendo } 150 \text { no braço ribociclibe e } 184 \text { no placebo. A SLP média não } \\
\text { foi atingida no braço ribociclibe e, no placebo, foi } 5 \text { meses mais longa em pacientes } \geq 65 \\
\text { anos do que naqueles }<65 \text { anos }(18,4 \text { e } 13 \text { meses, respectivamente). Os dados do estudo de } \\
\text { fase } 3 \text { randomizado MONALEESA-2 indicam que o ribociclibe mais letrozol é eficaz como } \\
\text { tratamento de primeira linha em pacientes idosos com câncer de mama avançado RH+. A } \\
\text { combinação está associada a um bom perfil de tolerabilidade em pacientes idosas. }\end{array}$ \\
\hline 2019 & Multinacional & Johnston et al. & $\begin{array}{l}\text { MONARCH } 3 \text { final PFS: a } \\
\text { randomized study of abemaciclib as } \\
\text { initial therapy for advanced breast } \\
\text { cancer. NPJ Breast Cancer. }\end{array}$ & $\begin{array}{l}\text { Apresentar a análise final pré } \\
\text { planejada de SLP para o ensaio } \\
\text { clínico MONARCH } 3 \text { com } \\
\text { análises detalhadas de endpoints } \\
\text { associado a resposta objetiva, } \\
\text { foram incluídos redução do } \\
\text { tumor e duração da resposta. }\end{array}$ & $\begin{array}{l}\text { Estudo randomizado, duplo cego, de fase } 3 \text { de abemaciclibe ou placebo }(150 \mathrm{mg} \text { duas vezes } \\
\text { ao dia, continuo) com um IA não esteroide }(1 \mathrm{mg} \text { anastrozol ou } 2,5 \mathrm{mg} \text { letrozol, } \\
\text { diariamente). } 493 \text { mulheres na pós-menopausa com câncer de mama avançado RH+/HER2- } \\
\text { sem terapia sistêmica anterior. } \\
\text { A taxa de sobrevida livre de progressão média foi de } 28,18 \text { meses com abemaciclibe e } 14,76 \\
\text { com placebo. A pesquisa demonstrou que as pacientes que receberam a combinação de } \\
\text { abemaciclibe e IA não esteroide apresentaram melhores taxas de sobrevida livre de } \\
\text { progressão. }\end{array}$ \\
\hline 2019 & Japão & Seki et al. & $\begin{array}{l}\text { Efficacy and Safety of palbociclib and } \\
\text { Fulvestrant in Japanese Patients With } \\
\text { ER+/HER2Advanced/Metastatic } \\
\text { Breast Cancer. }\end{array}$ & $\begin{array}{l}\text { Verificar a eficácia e segurança } \\
\text { do palbociclibe } r \text { mais } \\
\text { fulvestranto em pacientes } \\
\text { japoneses. }\end{array}$ & $\begin{array}{l}\text { Foi conduzido um estudo retrospectivo abrangendo pacientes com câncer de mama } \\
\text { metastático RE+/ HER2- tratadas com fulvestranto }(\mathrm{n}=39) \text { ou palbociclibe mais } \\
\text { fulvestranto }(\mathrm{n}=31) \text { no Saitama Medical Center de julho de } 2012 \text { a novembro de } 2018 \text {. No } \\
\text { grupo com fulvestranto, } 92,3 \% \text { estavam na pós-menopausa em comparação com } 77,4 \% \text { no } \\
\text { grupo com palbociclibe-fulvestranto. A sobrevida livre de progressão média foi } 3,9 \text { meses } \\
\text { (fulvestranto) e } 13,3 \text { meses (palbociclibe mais fulvestranto). }\end{array}$ \\
\hline 2019 & Argentina & Waller et al. & $\begin{array}{l}\text { Real-World Treatment Patterns and } \\
\text { Clinical Outcomes in Patients } \\
\text { Receiving Palbociclib for Hormone } \\
\text { Receptor-Positive, Human Epidermal } \\
\text { Growth Factor Receptor 2-Negative } \\
\text { Advanced or Metastatic Breast Cancer } \\
\text { in Argentina: The IRIS Study. }\end{array}$ & $\begin{array}{l}\text { O estudo Ibrance Real World } \\
\text { Insights (IRIS) tem como } \\
\text { objetivo avaliar o palbociclibe } \\
\text { em pacientes com câncer de } \\
\text { mama avançado ou câncer de } \\
\text { mama metastático RH+/HER2- } \\
\text { no cenário do mundo real em } \\
\text { vários países globalmente. }\end{array}$ & $\begin{array}{l}\text { Os resultados relatados nesta pesquisa, são relacionados a pacientes inscritos no estudo IRIS } \\
\text { na Argentina. É um estudo retrospectivo de revisão dos prontuários médicos de mulheres } \\
\text { com câncer de mama avançado ou câncer de mama metastático RH+/HER2-, tratadas com } \\
\text { palbociclibe mais letrozol como terapia endócrina de primeira linha ou com palbociclibe } \\
\text { mais fulvestranto em mulheres com progressão da doença após terapia endócrina. A } \\
\text { pesquisa foi realizada entre agosto e novembro de } 2017 \text {, onde contaram com } 41 \text { médicos, } \\
\text { sendo } 40 \text { oncologistas e } 1 \text { ginecologista e } 162 \text { pacientes. } 105 \text { pacientes foram tratados com } \\
\text { palbociclibe mais letrozol e } 57 \text { pacientes foram tratados com palbociclibe mais fulvestranto. } \\
99 \text { pacientes receberam tratamento de câncer de mama precoce, incluindo quimioterapia } \\
\text { adjuvante. A taxa de sobrevida livre de progressão, nos pacientes que receberam } \\
\text { palbociclibe mais letrozol em } 12 \text { meses foi de } 85 \% \text {, já aos } 18 \text { meses, } 85 \% \text { dos pacientes se } \\
\text { mantiveram livres de progressões. Já os pacientes que receberam palbociclibe e fulvestranto } \\
\text { apresentaram taxa de sobrevida livre de progressão em } 6 \text { meses de } 95 \% \text { no geral. }\end{array}$ \\
\hline 2019 & EUA & Wilkie et al. & $\begin{array}{l}\text { Progression-Free Survival for Real- } \\
\text { World Use of Palbociclib in Hormone } \\
\text { Receptor-Positive Metastatic Breast } \\
\text { Cancer. }\end{array}$ & $\begin{array}{l}\text { Estabelecer a SLP de pacientes } \\
\text { tratados com palbociclibe com } \\
\text { um IA em um ambiente de } \\
\text { primeira linha do mundo real } \\
\text { para câncer de mama } \\
\text { metastático RH+ e HER2-. }\end{array}$ & $\begin{array}{l}\text { Foi conduzido um estudo de revisão de coorte retrospectivo, aprovado pelo conselho de } \\
\text { revisão institucional, em um único centro. O estudo abrangeu } 70 \text { pacientes, que receberam } \\
\text { palbociclibe mais um IA. A SLP média para o tratamento de primeira linha foi de } 26,4 \\
\text { meses. Não houveram diferenças significativas na SLP entre as doses finais toleradas de } \\
\text { palbociclibe: } 125 \mathrm{mg} \text { ( } 22,6 \text { meses), } 100 \mathrm{mg} \text { (não atingida), } 75 \mathrm{mg} \text { ( } 27,7 \text { meses). O uso de } \\
\text { palbociclibe em um ambiente de mundo real demonstrou uma SLP média semelhante à } \\
\text { constatada no estudo PALOMA-2 no tratamento de primeira linha de câncer de mama } \\
\text { metastático RH+/HER2-. Além disso, houve maior incidência de redução de doses, } \\
\text { demonstrando que a redução da dosagem de palbociclibe na primeira linha de tratamento da } \\
\text { doença metastática não altera seu efeito na SLP. }\end{array}$ \\
\hline
\end{tabular}




\begin{tabular}{|c|c|c|c|c|c|}
\hline 2019 & Multinacional & Yardley et al. & $\begin{array}{l}\text { Efficacy and Safety of Ribociclib With } \\
\text { Letrozole in US Patients Enrolled in } \\
\text { the MONALEESA-2 Study. }\end{array}$ & $\begin{array}{l}\text { Apresentar os resultados do } \\
\text { subconjunto de pacientes norte- } \\
\text { americanos inscritos no } \\
\text { MONALEESA-2. }\end{array}$ & $\begin{array}{l}\text { Foi realizado um estudo randomizado, duplo-cego, controlado por placebo, de fase } 3 \text { de } \\
\text { ribociclibe mais letrozol ou placebo mais letrozol sendo conduzido em } 223 \text { centros, em } 29 \\
\text { países, incluindo } 74 \text { centros de estudo nos Estados Unidos. Os pacientes selecionados foram } \\
\text { as mulheres na pós-menopausa com câncer de mama avançado RH+/HER2- sem tratamento } \\
\text { prévio para doença avançada foram aleatoriamente selecionadas }(1: 1) \text { para receberem } \\
\text { ribociclibe } 600 \mathrm{mg} / \mathrm{d} \text { ( } 3 \text { semanas de tratamento/1 semana de pausa) com letrozol } 2,5 \mathrm{mg} / \mathrm{d} \\
\text { (contínuo) ou placebo com letrozol. } 213 \text { pacientes norte-americanos foram inscritos no } \\
\text { MONALESA-2 (ribociclibe, } \mathrm{n}=100 ; \text { placebo, } \mathrm{n}=113 \text { ). A SLP média foi de } 27,6 \text { meses } \\
\text { com ribociclibe e } 15,0 \text { meses com placebo (razão de risco, } 0,43 \text { ). } \\
\text { Chegou-se à conclusão que a combinação de ribociclibe com letrozol é mais eficaz que o } \\
\text { letrozol sozinho, resultado que apoia a combinação como tratamento de primeira linha para } \\
\text { pacientes com câncer de mama avançado RH+/HER2-. }\end{array}$ \\
\hline 2020 & Eslovênia & Kovač et al. & $\begin{array}{l}\text { Efficacy and safety of selective cyclin- } \\
\text { dependent kinases } 4 / 6 \text { inhibitors in } \\
\text { hormone-receptor-positive, HER } 2- \\
\text { negative advanced breast cancer - } \\
\text { results from a real-world setting. }\end{array}$ & $\begin{array}{l}\text { Os objetivos primários foram o } \\
\text { tempo até a falha do tratamento } \\
\text { e a sobrevida global, analisados } \\
\text { através do método de Kaplan- } \\
\text { Meier, os objetivos secundários } \\
\text { foram a taxa de benefício clínico } \\
\text { (TBC) e segurança. }\end{array}$ & 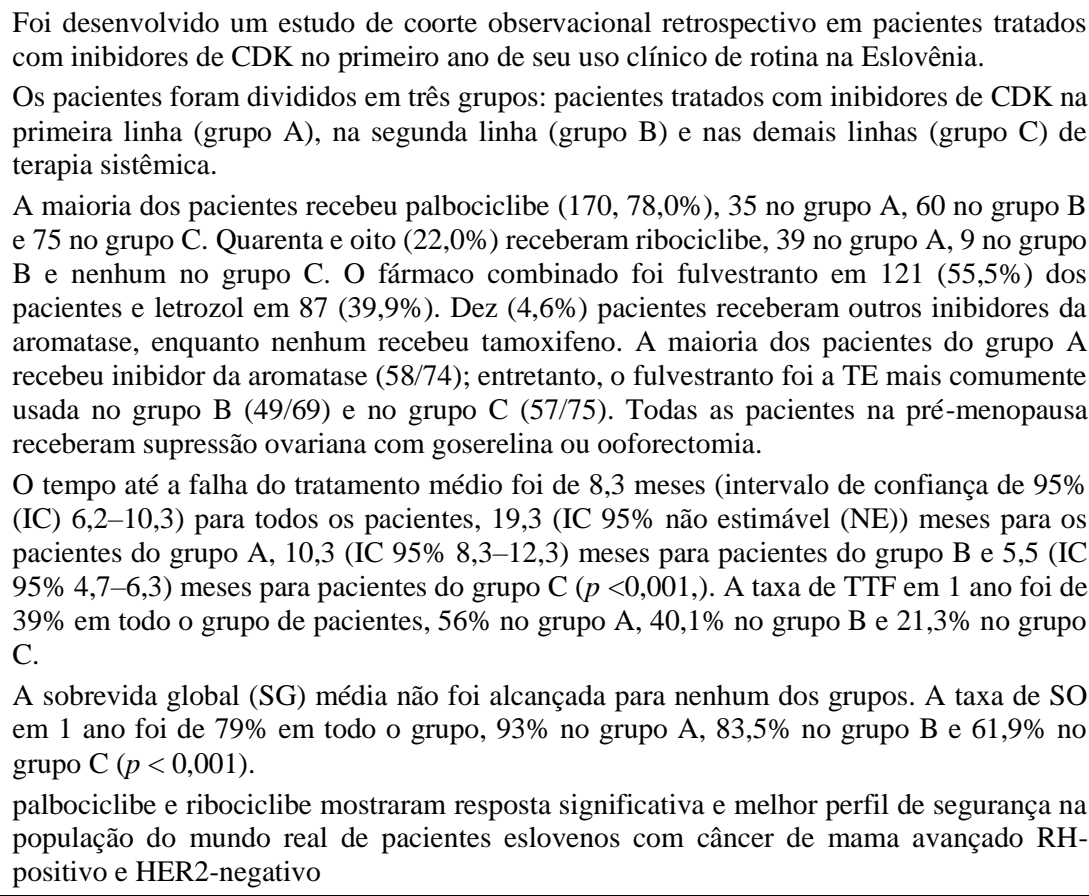 \\
\hline 2020 & China & Lei et al. & 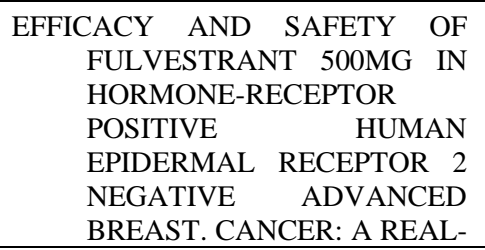 & $\begin{array}{l}\text { Investigar a eficácia e segurança } \\
\text { de fulvestranto em pacientes } \\
\text { chinesas RH+/ HER2- com } \\
\text { câncer de mama avançado. }\end{array}$ & $\begin{array}{l}\text { Decorreu um estudo retrospectivo do mundo real. Participaram pacientes com câncer de } \\
\text { mama avançado RH+/ HER2- que receberam fulvestranto } 500 \text { mg de janeiro de } 2015 \text { a } \\
\text { dezembro de } 2018 \text { no Hospital do Câncer de Pequim. } \\
\text { No total de } 303 \text { pacientes inscritos, } 255 \text { ( } 84,2 \% \text { ) pacientes estavam na pós-menopausa no } \\
\text { início do tratamento com fulvestranto e } 264 \text { pacientes }(87,1 \%) \text { tinham câncer de mama } \\
\text { avançado. A sobrevida livre de progressão (SLP) média (intervalo de confiança de } 95 \% \text { ) foi }\end{array}$ \\
\hline
\end{tabular}




\begin{tabular}{|c|c|c|c|c|c|}
\hline & & & WORLD STUDY IN CHINA. & & $\begin{array}{l}\text { de } 14,1 \text { meses }(10,1-18,0) \text { para a primeira linha. Os dados de sobrevivência foram } \\
\text { insuficientes para observar a média de sobrevida global. } \\
\text { O estudo concluiu que as pacientes que receberam o fulvestranto como tratamento de } \\
\text { primeira linha responderam significativamente melhor, com uma SLP mais longa para } \\
\text { pacientes com carga tumoral leve, sem quimioterapia paliativa antes de fulvestranto e } \\
\text { doença longa - intervalo livre. Para os pacientes que receberam fulvestranto após } \\
\text { quimioterapia paliativa a SLP foi maior no grupo de tratamento de manutenção do que } \\
\text { aqueles que progrediram após a quimioterapia. }\end{array}$ \\
\hline 2020 & EUA & $\begin{array}{l}\text { Skinner, Olufade, } \\
\text { Walker, \& } \\
\text { Schwartzberg. }\end{array}$ & $\begin{array}{l}\text { Real-world effectiveness of fulvestrant } \\
\text { monotherapy as first endocrine } \\
\text { treatment in patients with metastatic } \\
\text { breast cancer. }\end{array}$ & $\begin{array}{l}\text { Avaliar a eficácia do uso de } \\
\text { fulvestranto no lugar de IA } \\
\text { como terapia endócrina de } \\
\text { primeira linha em pacientes do } \\
\text { mundo real com câncer de mama } \\
\text { metastático. }\end{array}$ & $\begin{array}{l}\text { Trata-se de um estudo observacional retrospectivo baseado em dados extraídos de } \\
\text { prontuários eletrônicos. No total, foram incluídos } 121 \text { pacientes em uso de fulvestranto } \\
\text { como primeira linha de tratamento para câncer de mama metastático RH+/HER } 2 \text {, sendo que } \\
23 \text { destes eram virgens de tratamento endócrino. A sobrevida livre de progressão média foi } \\
\text { de } 12,2 \text { meses para todos os pacientes, e de } 18,7 \text { meses para pacientes virgens de tratamento. } \\
\text { O estudo evidenciou que pacientes sem terapia endócrina prévia obtiveram benefícios na } \\
\text { SLP similares aos de estudos clínicos anteriores. }\end{array}$ \\
\hline 2020 & Multinacional & Sledge et al. & $\begin{array}{l}\text { The Effect of Abemaciclib Plus } \\
\text { Fulvestrant on Overall Survival in } \\
\text { Hormone Receptor-Positive, ERBB2- } \\
\text { Negative Breast Cancer That } \\
\text { Progressed on Endocrine Therapy- } \\
\text { MONARCH 2: A Randomized } \\
\text { Clinical Trial. }\end{array}$ & $\begin{array}{l}\text { Comparar o efeito de } \\
\text { abemaciclibe mais fulvestranto } \\
\text { versus placebo mais fulvestranto } \\
\text { na sobrevida global no intervalo } \\
\text { pré-especificado de } \\
\text { MONARCH-2 (338 eventos) em } \\
\text { pacientes com câncer de mama } \\
\text { avançado RH+/HER2- que } \\
\text { progrediu durante a terapia } \\
\text { endócrina anterior. }\end{array}$ & $\begin{array}{l}\text { MONARCH } 2 \text { foi um estudo de fase } 3 \text { global, randomizado, duplo-cego, controlado por } \\
\text { placebo, que avaliou abemaciclibe ou placebo mais fulvestranto em mulheres com câncer } \\
\text { de mama avançado RH+/HER2-. } 669 \text { pacientes foram inscritas e designadas aleatoriamente } \\
\text { para receber abemaciclibe mais fulvestranto }(\mathrm{n}=446) \text { ou placebo mais fulvestranto }(\mathrm{n}= \\
223 \text { ). A sobrevida global média foi de } 46,7 \text { meses no braço do abemaciclibe e } 37,3 \text { meses } \\
\text { no placebo. Em relação à SLP média, foi de } 16,9 \text { meses no braço abemaciclibe e } 9,3 \text { meses } \\
\text { no placebo. Assim, o estudo MONARCH } 2 \text { demonstrou uma melhora significativa na } \\
\text { sobrevida global de } 9,4 \text { meses na terapia com abemaciclibe mais fulvestranto em pacientes } \\
\text { com câncer de mama avançado RH+/HER2-. }\end{array}$ \\
\hline 2020 & Multinacional & Zhang et al. & $\begin{array}{l}\text { MONARCH plus: abemaciclib plus } \\
\text { endocrine therapy in women with } \\
\text { HR+/HER2- advanced breast cancer: } \\
\text { the multinational randomized phase III } \\
\text { study. }\end{array}$ & $\begin{array}{l}\text { Comparar a eficácia, segurança } \\
\text { e tolerância de abemaciclibe } \\
\text { mais terapia endócrina, contra } \\
\text { apenas terapia endócrina em } \\
\text { mulheres no período pós- } \\
\text { menopausa, com câncer de } \\
\text { mama avançado RH+/HER2- da } \\
\text { China, Brasil, Índia e África do } \\
\text { Sul. }\end{array}$ & $\begin{array}{l}\text { Foi realizado um estudo multinacional de fase } 3 \text { duplo-cego, randomizado, controlado por } \\
\text { placebo em } 45 \text { instituições médicas de } 4 \text { países. O estudo foi composto por } 2 \text { coortes, A } \\
\text { (abemaciclibe mais IA contra placebo mais IA), com pacientes se terapia sistêmica prévia } \\
\text { para doença metastática, e B (abemaciclibe mais fulvestranto contra placebo mais } \\
\text { fulvestranto), com pacientes que progrediram de terapia endócrina anterior. } 463 \text { pacientes } \\
\text { participaram do estudo divididos entre as coortes A (n = } 306 \text {, com } 207 \text { no braço } \\
\text { abemaciclibe e } 99 \text { no placebo) e B (n = } 157 \text {, com } 104 \text { no braço abemaciclibe e } 53 \text { no } \\
\text { placebo). Na coorte A, a SLP média não foi atingida no braço abemaciclibe, e foi de } 14,7 \\
\text { meses no placebo. Já na coorte B, a SLP média foi de } 11,5 \text { meses no braço abemaciclibe, e } \\
\text { de } 5,6 \text { meses no placebo. Assim, a combinação de abemaciclibe e terapia endócrina revelou } \\
\text { avanços significativos na SLP em uma população de mulheres na pós-menopausa dos países } \\
\text { estudados. Os dados somam à totalidade de evidências que comprovam os benefícios do } \\
\text { abemaciclibe em populações desses países, que geralmente não estão inclusos na maioria } \\
\text { dos estudos com inibidores de ciclina. }\end{array}$ \\
\hline 2021 & EUA & $\begin{array}{l}\text { Brufsky, Liu, Li, } \\
\text { McRoy, \& } \\
\text { Layman. }\end{array}$ & $\begin{array}{l}\text { Real-World Tumor Response of } \\
\text { Palbociclib Plus Letrozole Versus } \\
\text { Letrozole for Metastatic Breast Cancer } \\
\text { in US Clinical Practice. }\end{array}$ & $\begin{array}{l}\text { Avaliar a resposta tumoral do } \\
\text { mundo real de palbociclibe mais } \\
\text { letrozol versus letrozol sozinho } \\
\text { como tratamento de primeira } \\
\text { linha para pacientes com câncer } \\
\text { de mama metastático }\end{array}$ & $\begin{array}{l}\text { Foi realizada uma análise retrospectiva que incluíram paciente RH+/HER2- com câncer de } \\
\text { mama metastático e que receberam palbociclibe e letrozol ou somente letrozol como } \\
\text { tratamento de primeira linha entre fevereiro de } 2015 \text { e setembro de } 2018 \text {. O estudo abrangeu } \\
1.383 \text { mulheres, sendo que destas, } 754 \text { receberam a combinação de palbociclibe mais } \\
\text { letrozol e } 629 \text { receberam apenas letrozol. A SLP média foi de } 20 \text { meses em pacientes em } \\
\text { uso de palbociclibe mais letrozol, e de } 15,1 \text { meses naqueles que recebem apenas letrozol. Já }\end{array}$ \\
\hline
\end{tabular}




\begin{tabular}{|c|c|c|c|c|c|}
\hline & & & & $\begin{array}{l}\mathrm{RH}+/ \mathrm{HER} 2-\text { na prática clínica } \\
\text { de rotina dos EUA. }\end{array}$ & $\begin{array}{l}\text { a sobrevida global foi de } 43,4 \text { meses com letrozol sozinho, e não foi atingida com } \\
\text { palbociclibe mais letrozol. A pesquisa refere-se ao estudo clínico PALOMA-2 que traz o } \\
\text { uso do palbociclibe mais letrozol como terapia de primeira linha, tendo esta combinação } \\
\text { valor significativo na melhora da sobrevida livre de progressão média em comparação com } \\
\text { o placebo mais letrozol. }\end{array}$ \\
\hline 2021 & EUA & $\begin{array}{l}\text { García-Trevijano } \\
\text { Cabetas et al. }\end{array}$ & $\begin{array}{l}\text { Real-world experience of palbociclib } \\
\text { and ribociclib: novel oral therapy in } \\
\text { metastatic breast cancer. }\end{array}$ & $\begin{array}{l}\text { Fornecer uma experiência do } \\
\text { mundo real da eficácia e } \\
\text { toxicidade associadas ao } \\
\text { palbociclibe e ao ribociclibe e } \\
\text { para avaliar o impacto das } \\
\text { mudanças de tratamento na } \\
\text { progressão da doença. }\end{array}$ & $\begin{array}{l}\text { Realizou-se um estudo retrospectivo observacional, incluindo pacientes com câncer de } \\
\text { mama metastático RH+/HER2-. } 61 \text { pacientes participaram do estudo, sendo que } 33 \text { foram } \\
\text { tratadas com palbociclibe e } 28 \text { com ribociclibe. Em mulheres tratadas com palbociclibe a } \\
\text { SLP média foi de } 12,76 \text { meses }(51,5 \% \text { em } 12 \text { meses e } 37,7 \% \text { em } 18 \text { meses), e não foi atingida } \\
\text { no grupo tratado com ribociclibe ( } 78,6 \% \text { em } 12 \text { meses e } 68,9 \% \text { em } 18 \text { meses). A terapia } \\
\text { alvo contra as CDK } 4 / 6 \text { mudou a história natural da doença, atingindo maiores taxas de } \\
\text { sobrevida com perfil de toxicidade favorável. }\end{array}$ \\
\hline 2021 & Canadá & $\begin{array}{l}\text { Mycock, Zhan, } \\
\text { Taylor-Stokes, } \\
\text { Milligan, \& Mitra. }\end{array}$ & $\begin{array}{l}\text { Real-World Palbociclib Use in } \\
\text { HR+/HER2- Advanced Breast Cancer } \\
\text { in Canada: The IRIS Study. }\end{array}$ & $\begin{array}{l}\text { Fornecer dados do mundo real } \\
\text { específicos do Canadá, que } \\
\text { podem ser utilizados para } \\
\text { complementar os dados de } \\
\text { ensaios clínicos randomizados, } \\
\text { com amostra maior e mais } \\
\text { diversa. }\end{array}$ & $\begin{array}{l}\text { Foi realizada uma análise retrospectiva de prontuários de pacientes que receberam } \\
\text { palbociclibe em combinação com um inibidor de aromatase ou com fulvestranto. Foram } \\
\text { selecionados } 247 \text { pacientes, sendo que destes, } 214 \text { realizaram tratamento com palbociclibe } \\
\text { e letrozol, e } 33 \text { com palbociclibe e fulvestranto. Observou-se que nos pacientes em uso de } \\
\text { palbociclibe e letrozol, a taxa livre de progressão foi de } 90,3 \% \text { em } 12 \text { meses e } 78,2 \% \text { em } 18 \\
\text { meses. Já entre os pacientes em regime de palbociclibe e fulvestranto a taxa livre de } \\
\text { progressão foi de } 83,3 \% \text { em } 6 \text { meses. Devido ao tempo de tratamento limitado eà pequena } \\
\text { quantidade de pacientes em tratamento com palbociclibe e fulvestranto analisados, a taxa } \\
\text { livre de progressão após } 6 \text { meses não foi obtida. O estudo IRIS demonstrou que a eficácia } \\
\text { do palbociclibe em combinação com letrozol ou fulvestranto foi favorável. As taxas de } \\
\text { redução de doses foram baixas, sugerindo que essas combinações são bem toleradas em } \\
\text { ambientes de mundo real. }\end{array}$ \\
\hline 2021 & Multinacional & Neven et al. & $\begin{array}{l}\text { Abemaciclib plus fulvestrant in } \\
\text { hormone receptor-positive, human } \\
\text { epidermal growth factor receptor } 2- \\
\text { negative advanced breast cancer in } \\
\text { premenopausal women: subgroup } \\
\text { analysis from the MONARCH } 2 \text { trial. }\end{array}$ & $\begin{array}{l}\text { O objetivo principal foi a SLP } \\
\text { (sobrevida livre de progressão) } \\
\text { avaliada pelo investigador e os } \\
\text { objetivos secundários foram SG } \\
\text { (sobrevida global), taxa de } \\
\text { resposta objetiva, segurança e } \\
\text { tolerabilidade. }\end{array}$ & 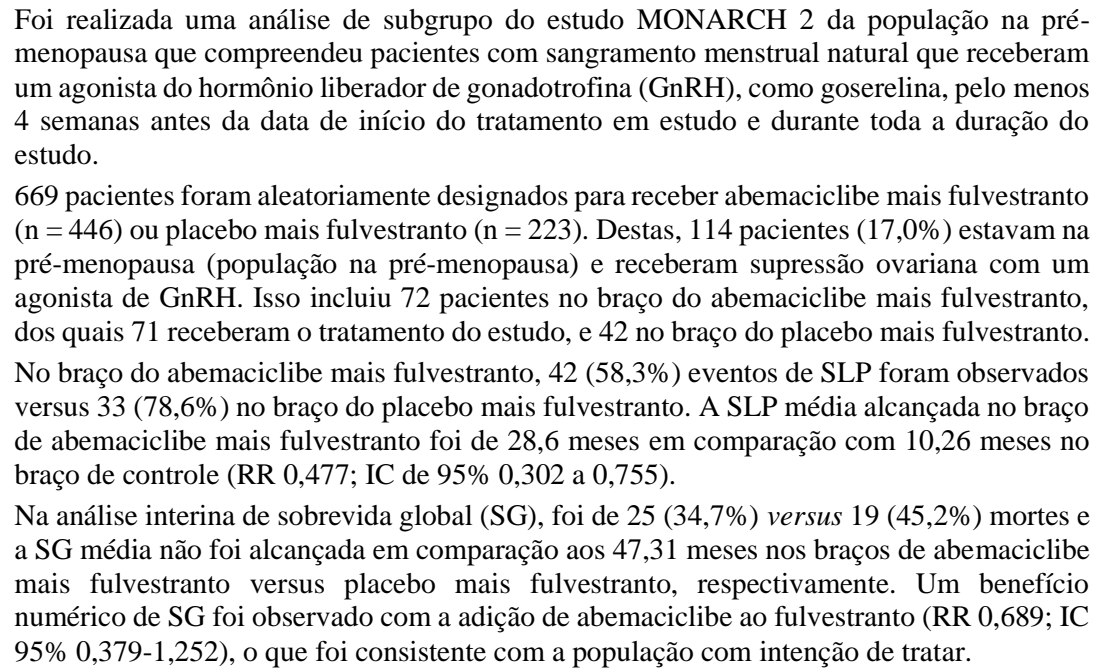 \\
\hline
\end{tabular}




\begin{tabular}{|c|c|c|c|c|c|}
\hline & & & & & $\begin{array}{l}\text { Concluiu-se que houve benefício para a população com intenção de tratar as que estavam } \\
\text { na pré-menopausa e fez uso do abemaciclibe mais fulvestranto (MONARCH 2). }\end{array}$ \\
\hline 2021 & $\begin{array}{l}\text { Leste Asiático: } \\
\text { Japão, Coréia e } \\
\text { Taiwan }\end{array}$ & Toi et al. & $\begin{array}{l}\text { Abemaciclib in combination with } \\
\text { endocrine therapy for East Asian } \\
\text { patients with RH+, HER2- advanced } \\
\text { breast cancer: MONARCH } 2 \& 3 \\
\text { trials. }\end{array}$ & $\begin{array}{l}\text { Avaliar a eficácia, segurança e } \\
\text { farmacocinética (PK) de } \\
\text { abemaciclibe em combinação } \\
\text { com terapia endócrina (TE) em } \\
\text { pacientes do Leste Asiático com } \\
\text { câncer de mama avançado, } \\
\text { receptor hormonal positivo } \\
\text { (RH+) e receptor de fator de } \\
\text { crescimento epidérmico humano } \\
2 \text { negativo (HER2-). }\end{array}$ & $\begin{array}{l}\text { Desenrolou-se uma análise post hoc de MONARCH } 2 \text { e MONARCH } 3 \text {. } \\
\text { No MONARCH 2, os pacientes foram randomizados em uma proporção de } 2: 1 \text { para receber } \\
\text { abemaciclibe }+ \text { fulvestranto ou placebo + fulvestranto. No MONARCH } 3 \text {, os pacientes } \\
\text { foram designados aleatoriamente em uma proporção de } 2: 1 \text { para receber abemaciclibe + IA } \\
\text { ou placebo + IA. } \\
\text { MONARCH 2: Um total de } 70(47,6 \%) \text { eventos de SLP no braço com abemaciclibe + } \\
\text { fulvestranto e } 51(78,5 \%) \text { no braço com placebo + fulvestranto ocorreram pelo corte de } \\
\text { dados em pacientes do Leste Asiático. A média de sobrevivência livre de progressão (SLP) } \\
\text { foi de } 21,2 \text { meses no braço de abemaciclibe + fulvestranto e } 11,6 \text { meses no braço de placebo } \\
\text { + fulvestranto (RR, } 0,520 ; \text { IC de } 95 \%, 0,362 \text { a } 0,747 ; ;<0,001) \text {. } \\
\text { MONARCH 3: Na população do Leste Asiático, } 36(35,3 \%) \text { eventos de SLP ocorreram no } \\
\text { braço abemaciclibe + IA, e } 30 \text { ( } 71,4 \%) \text { ocorreram no braço placebo + IA. A SLP média não } \\
\text { foi alcançada no braço abemaciclibe + IA e foi de } 12,82 \text { meses no braço placebo + IA (RR, } \\
\text { 0,326; IC de } 95 \%, 0,200 \text { a } 0,531, P<0,001) \text {. } \\
\text { Concluiu-se que a população do Leste Asiático de MONARCH } 2 \text { e } 3 \text { tiveram maiores } \\
\text { benefícios com abemaciclibe em combinação com IAs (letrozol e anastrozol) ou com } \\
\text { fulvestranto. }\end{array}$ \\
\hline
\end{tabular}

Source: Authors (2021)

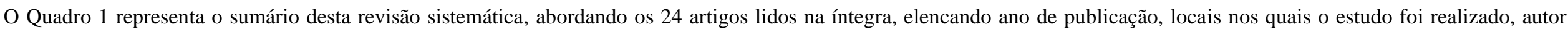

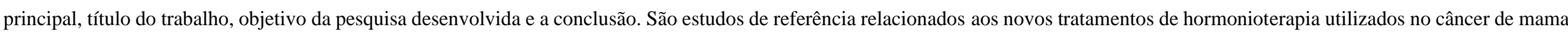

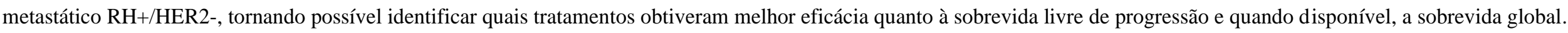




\section{Discussão}

A combinação de inibidor de CDK 4 e 6 (abemaciclibe, palbociclibe e ribociclibe) com IA (anastrozol, letrozol) obteve melhores resultados quanto à SLP para tratamento de primeira linha do câncer de mama metastático RH+/HER2-, sendo adotada pelas principais diretrizes das sociedades americana e europeia de Oncologia, conforme mencionado nas diretrizes de tratamentos oncológicos recomendados pela SBOC (2021).

O que vai determinar se a paciente vai fazer uma terapia combinada, monoterapia ou qual medicamento, são as características inerentes a cada indivíduo, tumor, doença, agente terapêutico e outros fatores como, disponibilidade de pesquisa clínica e condições sociais. Como recomendado pelo INCA (2019a), quando há metástase é imprescindível zelar pela qualidade de vida da paciente, assim, balanceando o controle da doença e a possibilidade do aumento da SLP.

Os estudos observacionais trouxeram uma visão do mundo real sobre os inibidores de CDK 4 e 6, demonstrando eficácia semelhante àquela encontrada nos grandes ensaios clínicos randomizados internacionais como foi evidenciado por outras revisões realizadas (Battisti et al., 2018; Li et al., 2020; Piezzo et al., 2020). A seguir, apresentam-se uma análise da eficácia dos regimes de tratamento identificados a partir deste estudo:

- Palbociclibe + letrozol: apresenta alta eficácia como tratamento de primeira linha para mulheres na pós-menopausa com câncer de mama metastático RH+/HER2-, que não receberam terapia sistêmica prévia para o câncer de mama, conforme demonstrado pelos estudos PALOMA-1 e PALOMA-2, e pelo estudo observacional retrospectivo IRIS. Além de melhor índice de sobrevida livre de progressão, com média de 26,5 meses (95\% IC 24,8-27,4), evidenciou-se maiores taxas de resposta objetiva ao tratamento (63,1\% dos pacientes), quando comparado com letrozol em monoterapia (Brufsky et al., 2021; Finn et al., 2015; Kovač et al., 2020; Mycock et al., 2021; Rugo et al., 2016; Waller et al., 2019; Wilkie et al., 2019).

- Ribociclibe + letrozol: o tratamento combinado foi avaliado pelo ensaio clínico MONALEESA-2 e resultou em SLP média de 27,6 meses, demonstrando benefício significativo na sobrevida livre de progressão em mulheres na pósmenopausa com câncer de mama metastático RH+/HER2-, quando comparada com o uso de letrozol mais placebo. Foi verificado ainda que tal benefício se estende por todos subgrupos analisados pelos estudos, comprovando sua alta eficácia na primeira linha de tratamento (García-Trevijano Cabetas et al., 2021; Hortobagyi et al., 2016; O'Shaughnessy et al., 2018; Sonke et al., 2018; Yardley et al., 2019).

- Abemaciclibe + letrozol: este regime de tratamento foi estudado nos ensaios clínicos randomizados MONARCH 3 e MONARCH plus, que evidenciaram aumento expressivo da sobrevida livre de progressão, com média de 28,2 meses, e maior taxa de resposta objetiva quando comparado com o uso de placebo mais letrozol, $61,9 \%$ e $41,8 \%$ respectivamente, como primeira linha de tratamento para o câncer de mama metastático RH+/HER2-. (Goetz et al., 2017; Johnston et al., 2019; Toi et al., 2021; Zhang et al., 2020).

- Abemaciclibe + fulvestranto: é utilizado como tratamento de primeira linha em mulheres com câncer de mama que progrediram para doença metastática após terapia endócrina prévia. Os ensaios clínicos MONARCH 2 e MONARCH plus apresentaram sobrevida livre de progressão média de 16,5 meses (95\% IC 11,5-21,2), notando-se maior benefício dentre o subgrupo de mulheres na pré-menopausa, cuja SLP média foi de 28,6 meses. A análise da sobrevida global na população do MONARCH 2, demonstrou aumento de 9,4 meses, com SG média de 46,7 meses no braço abemaciclibe e 37,3 para o placebo (Neven et al., 2021; Sledge et al., 2020; Toi et al., 2021; Zhang et al., 2020).

- Palbociclibe + fulvestranto: foi a primeira combinação com um inibidor de CDK 4 e 6 aprovada para o tratamento de mulheres com câncer de mama que progrediram para doença metastática após terapia hormonal prévia, sendo 
geralmente empregada como terapia de segunda linha. No contexto de tratamento de primeira linha, sua eficácia é reduzida, com sobrevida livre de progressão em torno de 18,7 meses (García-Trevijano Cabetas et al., 2021; Mycock et al., 2021; Seki et al., 2019; Waller et al., 2019).

- Monoterapia com fulvestranto: demonstrou ser mais eficaz que a monoterapia com inibidores de aromatase para mulheres na pós-menopausa com câncer de mama metastático RH+/HER2-, de acordo com os resultados obtidos nos estudos FALCON e FIRST. Foram evidenciadas sobrevida livre de progressão média de 16,5 meses (95\% IC 12,2-23,4) e sobrevida global média de 54,1 meses (Ellis et al., 2015; Lei et al., 2020; Robertson et al., 2012; Robertson et al., 2016; Skinner et al., 2020).

Apesar de terem revolucionado o tratamento de primeira linha para o câncer de mama metastático RH+/HER2-, os inibidores de CDK 4 e 6 são linhas de tratamento que não estão disponíveis na rede de saúde pública, devido ao alto custo da terapia. Em virtude disso, a abordagem terapêutica nessa rede ainda se baseia no uso de inibidores da aromatase, tamoxifeno e fulvestranto (Portaria conjunta n. 19, 2018).

\section{Conclusão}

Deste modo, esta revisão sistemática da literatura avaliou trabalhos diretamente relacionados à primeira linha de tratamento do câncer de mama metastático RH+/HER2-, englobando os ensaios clínicos PALOMA-2, MONALEESA-2, MONARCH-3, dentre outros de significativa importância. Os inibidores de CDK 4/6 são novidade no que diz respeito ao tratamento do câncer de mama metastático RH+/HER2-, tendo grandes resultados quanto à SLP quando combinados com IAs ou fulvestranto, no entanto ainda não são encontrados no Sistema Único de Saúde (SUS). A melhor sobrevida livre de progressão média foi de 28,2 meses, alcançada com a combinação abemaciclibe mais letrozol. No que se refere à SG, o melhor tempo obtido foi de 54,1 meses com fulvestranto em monoterapia.

Durantes as pesquisas, foi observado que em grande parte dos artigos estudados não obtiveram dados suficientes sobre a sobrevida global das pacientes em tratamento de primeira linha para o câncer de mama metastático RH+/HER2-. Portanto, sugere-se que estudos futuros possuam foco na determinação da sobrevida global média das mulheres em uso de inibidores de CDK 4/6 em combinação com inibidores da aromatase ou fulvestranto.

\section{Financiamento}

Não houve financiamento para o presente estudo.

\section{Declaração de conflito de interesse}

Os autores declaram não haver conflito de interesse.

\section{Referências}

Battisti, N., De Glas, N., Sedrak, M. S., Loh, K. P., Liposits, G., Soto-Perez-de-Celis, E., Krok-Schoen, J. L., Menjak, I. B., \& Ring, A. (2018). Use of cyclindependent kinase 4/6 (CDK4/6) inhibitors in older patients with ER-positive HER2-negative breast cancer: Young International Society of Geriatric Oncology review paper. Ther. Adv. Med. Oncol., 10, Artigo 1758835918809610.

Brufsky, A., Liu, X., Li, B., McRoy, L., \& Layman, R. M. (2021). Real-World Tumor Response of Palbociclib Plus Letrozole Versus Letrozole for Metastatic Breast Cancer in US Clinical Practice. Target Oncol., 16(5), 601-611.

Ellis, M. J., Llombart-Cussac, A., Feltl, D., Dewar, J. A., Jasiówka, M., Hewson, N., Rukazenkov, Y., \& Robertson, J. F. (2015). Fulvestrant 500 mg Versus Anastrozole $1 \mathrm{mg}$ for the First-Line Treatment of Advanced Breast Cancer: Overall Survival Analysis From the Phase II FIRST Study. J. Clin. Oncol., 33(32), 3781-3787.

Finn, R. S., Crown, J. P., Lang, I., Boer, K., Bondarenko, I. M., Kulyk, S. O., Ettl, J., Patel, R., Pinter, T., Schmidt, M., Shparyk, Y., Thummala, A. R., Voytko, N. L., Fowst, C., Huang, X., Kim, S. T., Randolph, S., \& Slamon, D. J. (2015). The cyclin-dependent kinase 4/6 inhibitor palbociclib in combination with 
letrozole versus letrozole alone as first-line treatment of oestrogen receptor-positive, HER2-negative, advanced breast cancer (PALOMA-1/TRIO-18): a randomised phase 2 study. Lancet Oncol., 16(1), 25-35.

Galvão, T. F., Pansani, T. S. A., \& Harrad, D. (2015) Principais itens para relatar Revisões sistemática e Meta-análises: a recomendação PRISMA. Epidemiol. Serv. Saúde, 24(2), 335-342.

García-Trevijano Cabetas, M., Lucena Martínez, P., Jiménez Nácher, I., Díaz Almirón, M., Zamora Auñón, P., \& Herrero Ambrosio, A. (2021). Real-world experience of palbociclib and ribociclib: novel oral therapy in metastatic breast cancer. Int. J. Clin. Pharm., 43(4), 893-899.

Goetz, M. P., Toi, M., Campone, M., Sohn, J., Paluch-Shimon, S., Huober, J., Park, I. H., Trédan, O., Chen, S. C., Manso, L., Freedman, O. C., Jaliffe, G. G., Forrester, T., Frenzel, M., Barriga, S., Smith, I. C., Bourayou, N., \& Di Leo, A. (2017). MONARCH 3: Abemaciclib As Initial Therapy for Advanced Breast Cancer. J. Clin. Oncol., 35(32), 3638-3646.

Goldhirsch, A., Wood, W. C., Coates, A. S., Gelber, R. D., Thürlimann, B., Senn, H. J., \& Panel members. (2011). Strategies for subtypes - dealing with the diversity of breast cancer: highlights of the St Gallen International Expert Consensus on the Primary Therapy of Early Breast Cancer 2011. Annals of Oncology, $22(8), 1736-1747$.

Hortobagyi, G. N., Stemmer, S. M., Burris, H. A., \& Yap, Y. S. (2016). Ribociclib as First-Line Therapy for HR-Positive, Advanced Breast Cancer. N. Engl. J. Med., 375, 1738-1748.

Instituto Nacional de Câncer José Alencar Gomes da Silva. (2019a). A situação do câncer de mama no Brasil: síntese de dados dos sistemas de informação. INCA.

Instituto Nacional de Câncer José Alencar Gomes da Silva. (2019b). Estimativa 2020: incidência de câncer no Brasil. INCA.

Instituto Nacional de Câncer José Alencar Gomes da Silva. (2021a). Atlas da mortalidade. https://www.inca.gov.br/MortalidadeWeb/pages/Modelo01/consultar.xhtml;jsessionid=D74E682A80B15156B5E577DD6522DEE1\#panelResultado.

Instituto Nacional de Câncer José Alencar Gomes da Silva. (2021b). Câncer de mama - versão para Profissionais de Saúde. https://www.inca.gov.br/tipos-decancer/cancer-de-mama/profissional-de-saude.

Johnston, S., Martin, M., Di Leo, A., Im, S. A., Awada, A., Forrester, T., Frenzel, M., Hardebeck, M. C., Cox, J., Barriga, S., Toi, M., Iwata, H., \& Goetz, M. P. (2019). MONARCH 3 final PFS: a randomized study of abemaciclib as initial therapy for advanced breast cancer. npj Breast Cancer, 5 , Artigo 5.

Kovač, A., Matos, E., Kuhar, C. G., Čakš, M., Ovčariček, T., Mencinger, M., Humar, M., \& Borštnar, S. (2020). Efficacy and safety of selective cyclin-dependent kinases 4/6 inhibitors in hormone-receptor-positive, HER2-negative advanced breast cancer - results from a real-world setting. Cancer Treat. Res. Commun., 25, Artigo 100201 .

Lei, W., Li, H., Song, G., Zhang, R., Ran, R., Yan, Y., Di, L., \& Jiang, H. (2020). Efficacy and Safety of Fulvestrant 500mg in Hormone-receptor Positive Human Epidermal Receptor 2 Negative Advanced Breast Cancer: A Real-world Study in China. J. Cancer, 11(22), 6612-6622.

Li, J., Huo, X., Zhao, F., Ren, D., Ahmad, R., Yuan, X., Du, F., \& Zhao, J. (2020). Association of cyclin-dependent kinases 4 and 6 inhibitors with survival in patients with hormone receptor-positive metastatic breast cancer: a systematic review and meta-analysis. JAMA Netw. Open, 3(10), Artigo e2020312.

Mycock, K., Zhan, L., Taylor-Stokes, G., Milligan, G., \& Mitra, D. (2021). Real-World Palbociclib Use in HR+/HER2- Advanced Breast Cancer in Canada: The IRIS Study. Curr. Oncol., 28(1), 678-688.

Neven, P., Rugo, H. S., Tolaney, S. M., Iwata, H., Toi, M., Goetz, M. P., Kaufman, P. A., Lu, Y., Haddad, N., Hurt. K. C., \& Sledge, G. W., Jr. (2021). Abemaciclib plus fulvestrant in hormone receptor-positive, human epidermal growth factor receptor 2-negative advanced breast cancer in premenopausal women: subgroup analysis from the MONARCH 2 trial. Breast Cancer Res., 23, Artigo 87.

O’Shaughnessy, J., Petrakova, K., Sonke, G. S., Conte, P., Arteaga, C. L., Cameron, D. A., Hart, L. L., Villanueva, C., Jakobsen, E., Beck, J. T., Lindquist, D., Souami, F., Mondal, S., Germa, C., \& Hortobagyi, G. N. (2018). Ribociclib plus letrozole versus letrozole alone in patients with de novo HR+, HER2- advanced breast cancer in the randomized MONALEESA-2 trial. Breast Cancer Res. Treat., 168(1), 127-134.

Piezzo, M., Chiodini, P., Riemma, M., Cocco, S., Caputo, R., Cianniello, D., Di Gioia, G., Di Lauro, V., Rella, F. D., Fusco, G., Iodice, G., Nuzzo, F., Pacilio, C., Pensabene, M., \& De Laurentiis, M. (2020). Progression-free survival and overall survival of CDK 4/6 inhibitors plus endocrine therapy in metastatic breast cancer: a systematic review and meta-analysis. Int. J. Mol. Sci., 21(17), Artigo 6400.

Portaria conjunta n. 19, de 3 de julho de 2018. (2018). Aprova as Diretrizes Diagnósticas e Terapêuticas do Carcinoma de Mama. Brasília. Secretaria de Atenção à Saúde e Secretaria de Ciência, Tecnologia e Insumos Estratégicos.

Robertson, J. F., Lindemann, J. P., Llombart-Cussac, A., Rolski, J., Feltl, D., Dewar, J., Emerson, L., Dean, A., \& Ellis, M. J. (2012). Fulvestrant 500 mg versus anastrozole $1 \mathrm{mg}$ for the first-line treatment of advanced breast cancer: follow-up analysis from the randomized 'FIRST' study. Breast Cancer Res. Treat., $136(2), 503-511$.

Robertson, J., Bondarenko, I. M., Trishkina, E., Dvorkin, M., Panasci, L., Manikhas, A., Shparyk, Y., Cardona-Huerta, S., Cheung, K. L., Philco-Salas, M. J., Ruiz-Borrego, M., Shao, Z., Noguchi, S., Rowbottom, J., Stuart, M., Grinsted, L. M., Fazal, M., \& Ellis, M. J. (2016). Fulvestrant 500 mg versus anastrozole 1 $\mathrm{mg}$ for hormone receptor-positive advanced breast cancer (FALCON): an international, randomised, double-blind, phase 3 trial. Lancet, 388(10063), 2997-3005.

Rugo, H. S., Finn, R. S, Gelmon, K., Joy, A. A., Harbeck, N., Castrellon, A., Mukai, H., Walshe, J. M., Mori, A., Gauthier, E., Lu, D. R., Bananis, E., Martin, M., \& Diéras, V. (2020). Progression-free Survival Outcome Is Independent of Objective Response in Patients With Estrogen Receptor-positive, Human Epidermal Growth Factor Receptor 2-negative Advanced Breast Cancer Treated With Palbociclib Plus Letrozole Compared With Letrozole: Analysis From PALOMA-2. Clin. Breast Cancer, 20(2), e173-e180. 
Research, Society and Development, v. 10, n. 14, e85101421940, 2021

Seki, H., Sakurai, T., Maeda, Y., Oki, N., Aoyama, M., Yamaguchi, R., Tokuda, T., Kaburagi, T., Okumura, T., Karahashi, T., Nakajima, K., Higeta, K., \& Shimizu, K. (2019). Efficacy and Safety of Palbociclib and Fulvestrant in Japanese Patients With ER+/HER2- Advanced/Metastatic Breast Cancer. In Vivo, 33(6), 2037-2044.

Skinner, K. E., Olufade, T., Walker, M. S., \& Schwartzberg, L. S. (2020). Real-world effectiveness of fulvestrant monotherapy as first endocrine treatment in patients with metastatic breast cancer. Breast J., 26(2), 112-119.

Sledge, G. W., Jr., Toi, M., Neven, P., Sohn, J., Inoue, K., Pivot, X., Burdaeva, O., Okera, M., Masuda, N., Kaufman, P. A., Koh, H., Grischke, E. M., Conte, P., Lu, Y., Barriga, S., Hurt, K., Frenzel, M., Johnston, S., \& Llombart-Cussac, A. (2020). The Effect of Abemaciclib Plus Fulvestrant on Overall Survival in Hormone Receptor-Positive, ERBB2-Negative Breast Cancer That Progressed on Endocrine Therapy-MONARCH 2: A Randomized Clinical Trial. JAMA Oncol., 6(1), 116-124.

Sociedade Brasileira de Oncologia Clínica. (2021). Mama: doença metastática. SBOC.

Sonke, G. S., Hart, L. L., Campone, M., Erdkamp, F., Janni, W., Verma, S., Villanueva, C., Jakobsen, E., Alba, E., Wist, E., Favret, A. M., Bachelot, T., Hegg, R., Wheatley-Prince, P., Souami, F., Sutradhar, S., Miller, M., Germa, C., \& Burris, H. A. (2018). Ribociclib with letrozole vs letrozole alone in elderly patients with hormone receptor-positive, HER2-negative breast cancer in the randomized MONALEESA-2 trial. Breast Cancer Res. Treat., 167(3), 659-669.

Toi, M., Inoue, K., Masuda, N., Iwata, H., Sohn, J., Hae Park, I., Im, S. A., Chen, S. C., Enatsu, S., Turner, P. K., André, V., Hardebeck, M. C., Sakaguchi, S., Goetz, M. P., \& Sledge, G. W., Jr. (2021). Abemaciclib in combination with endocrine therapy for East Asian patients with HR+, HER2- advanced breast cancer: MONARCH 2 \& 3 trials. Cancer Sci., 112(6), 2381-2392.

Waller, J., Mitra, D., Mycock, K., Taylor-Stokes, G., Milligan, G., Zhan, L., \& Iyer, S. (2019). Real-World Treatment Patterns and Clinical Outcomes in Patients Receiving Palbociclib for Hormone Receptor-Positive, Human Epidermal Growth Factor Receptor 2-Negative Advanced or Metastatic Breast Cancer in Argentina: The IRIS Study. J. Glob. Oncol., 5, Artigo JGO1800239.

Wilkie, J., Schickli, M. A., Berger, M. J., Lustberg, M., Reinbolt, R., Noonan, A., Ramaswamy, B., Sardesai, S., VanDeusen, J., Wesolowski, R., Williams, N., Stover, D. G., Li, J., \& Vargo, C. A. (2020). Progression-Free Survival for Real-World Use of Palbociclib in Hormone Receptor-Positive Metastatic Breast Cancer. Clin. Breast Cancer, 20(1), 33-40.

Yardley, D. A., Hart, L., Favret, A., Blau, S., Diab, S., Richards, D., Sparano, J., Beck, J. T., Richards, P., Ward, P., Ramaswamy, B., Tsai, M., Blackwell, K., Pluard, T., Tolaney, S. M., Esteva, F. J., Truica, C. I., Alemany, C., Volas-Redd, G., Shtivelband, M., Purkayastha, D., Dalal, A. A., Miller, M., \& Hortobagyi, G. N. (2019). Efficacy and Safety of Ribociclib With Letrozole in US Patients Enrolled in the MONALEESA-2 Study. Clin. Breast Cancer, 19(4), 268-277.e1.

Zhang, Q. Y., Sun, T., Yin, Y. M., Li, H. P., Yan, M., Tong, Z. S., Oppermann, C. P., Liu, Y. P., Costa, R., Li, M., Cheng, Y., Ouyang, Q. C., Chen, X., Liao, N., Wu, X. H., Wang, X. J., Feng, J. F., Hegg, R., Kanakasetty, G. B., Coccia-Portugal, M. A., Han, R. B., Lu, Y., Chi, H. D., Jiang, Z. F., \& Hu, X. C. (2020). MONARCH plus: abemaciclib plus endocrine therapy in women with HR+/HER2- advanced breast cancer: the multinational randomized phase III study. Ther. Adv. Med. Oncol., 12, Artigo 1758835920963925. 